\title{
Use of Apitherapy as a Novel Practice in the Management of Oral Diseases: A Review of Literature
}

Syeda Arshiya Ara, Sajna Ashraf, Vini Arora, Prakash Rampure

\section{ABSTRACT}

Man has always been ignorant of the plethora of natural products that are available around him. In his search for newer treatment modalities in medicine, he has reached back to the source of several vital materials that are available in nature. These natural products are not only highly bioactive, they also have several interactions that are synergistic in preventing infections, promoting healing and preserving health in total.

Bees have been around much longer than humans and the pinnacle of their evolution has been the development of honey. This multifaceted material is vital to the survival of the species and plays a major role in the physiologic development and maturity of bees. Man has been harvesting this natural resource of infinite applications and has been using it in traditional medicine since time immemorial.

Developments in science have led to us having a better understanding of the ingredients present in bee products and it has generated great interest in its use for medical treatment. This is the field of apitherapy. Its applications in oral diseases are not widely known. It has certainly shown great promise as being the next gold mine of therapeutic medicines that are useful in managing many oral diseases.

Keywords: Apitherapy, Propolis, Bee venom therapy, Oral diseases, Dental use.

How to cite this article: Ara SA, Ashraf S, Arora V, Rampure P. Use of Apitherapy as a Novel Practice in the Management of Oral Diseases: A Review of Literature. J Contemp Dent 2013; 3(1):25-31.

\section{Source of support: Nil}

Conflict of interest: None declared

\section{INTRODUCTION}

Apitherapy is the use of honey bee products such as honey, bee venom, propolis and royal jelly for medicinal purposes. ${ }^{1-3}$ According to Dr Stefan Stangaciu, apitherapy, or 'bee therapy' (from the Latin word 'apis' which means bee) is defined as, 'the art and science of treatment and holistic healing through the honey bee and her products for the benefit of mankind and all the animal kingdom. ${ }^{1,2}$ Therapies involving the honeybee have existed for thousands of years and some may be as old as human medicine itself. ${ }^{1}$

Propolis is resinous material/sap that is collected after it oozes out from tree bark and bud. ${ }^{1}$ The term Propolis (bee glue) derives from 'pro' (Greek = before), and 'polis' city based on the fact that honeybees use propolis to narrow the opening to their hives. ${ }^{4}$ It has been characterized as an antibacterial, antiviral, anti-inflammatory, antioxidant and anticarcinogenic agent. ${ }^{2}$ After bees have collected propolis they mix it with wax flakes and their saliva in the hive. ${ }^{1}$ Though bees use propolis to reinforce their hive walls and protect the hives from infection, humans use these products to boost their immune system. ${ }^{1,2}$

Pollen (reproductive spores of seed-bearing plants) is collected by bees from flowers. Benefits of bee pollen extracts include detection and immunization against allergies. Pollen provide relief for bodily weakness, premature aging, constipation and weight loss. ${ }^{1,2}$ For use in apitherapy, practitioners prefer to have pollen that is as fresh as possible. ${ }^{5}$

Royal jelly is a thick, milky mix of nutrients, which is produced from a combination of honey and pollen. All of the bees in a hive consume this substance, but larvae that consume it exclusively and in high doses grow larger than the other bees, thus enabling them to become queens of the hive. ${ }^{1,2}$ Royal jelly is a concentrated source of many nutrients, including all the $\mathrm{B}$ vitamins, vitamins $\mathrm{A}, \mathrm{C}, \mathrm{D}$ and $\mathrm{E}$ and essential fatty acids. ${ }^{5}$

Bee venom therapy can be administered two ways: Directly from a bee sting or by a prepared injection. Bee venom causes inflammation where it is introduced in the body. The inflammation triggers the body to increase circulation to that point and to create anti-inflammatory hormones to relieve pain. By injecting bee venom directly to the joint that is painful, the body's anti-inflammatory response will treat the arthritic joint. ${ }^{1,2}$

\section{HISTORICAL REVIEW}

- Honey is the most ancient wound dressing known, mentioned by the Greek philosopher Aristoteles ${ }^{6}$ and it has continued to be used throughout the ages. Dioscorides (c 50 AD) wrote of honey being 'good for sunburn' and 'for all rotten and hollow ulcers'. ${ }^{1,6,7}$ More recently, honey has been reported to have an inhibitory effect to around 60 species of bacteria including aerobes and anaerobes, Gram-positives and Gram-negative microorganisms. $^{1,6}$

- The history of apitherapy can be traced back to the ancient Egyptians ${ }^{1}$ the first known prescription using 
honey was written on a clay tablet, found in the Euphrates valley and dating from somewhere between 2100 and 2000 BC. $^{5}$

- Hippocrates, the ancient Greek physician and 'father of medicine' listed the physical effects of honey: 'It causes heat, cleans sores and ulcers, softens hard ulcers of the lips, and heals carbuncles and running sores'.1,5

- The use of honey has been documented in several religious texts including the Vedas (a book of Hindu scriptures), the Bible and Quran., ${ }^{1,5}$

- In 1597, John Gerard wrote about the healing power of propolis in 'The History of Plant'., 1,6

- In the 1989 issue of the Journal of Royal Society Medicine an editorial expressed that 'the time has come for conventional medicine to lift the blinds off this 'traditional remedy' (honey) and to give it due recognition'. 1

\section{COMPOSITION OF HONEY (TABLE 1) ${ }^{1}$}

Honey is defined as a sweet liquid substance produced by bees from the nectar gathered from flowers and stores by them for food. The color and flavor are determined by the flowers used. ${ }^{1}$

\section{COMPOSITION OF PROPOLIS}

The composition of propolis varies greatly depending on its geographic and botanical origin. ${ }^{6}$

Propolis is composed of resin and balsams (50-60\%), pollen (5-10\%) and other constituents which are amino acids, minerals, vitamins A, B complex, bioflavonoid, phenols and aromatic compound. Flavenoids are well known plant compounds which have antibacterial, antifungal, antiviral, antioxidant, and anti-inflammatory properties. Cinnamic acid is a white crystalline acid, which is slightly soluble in water and is obtained from oil of cinnamon, or from balsams. ${ }^{8}$

\section{PROPERTIES OF HONEY AND PROPOLIS}

\section{Antimicrobial}

The antibacterial property of honey was first recognized in 1892 by van Ketel $^{1}$ and all examined types of propolis revealed a strong antibacterial activity ${ }^{6}$ (Table 2 ).

Important factors which influence the antibacterial effectiveness are as follows:

1. Its hygroscopic properties: This effect is based on high osmotic properties so it can extract water from bacterial cells and cause them to die. Honey, like other saturated sugar syrups and sugar pastes, has an osmolarity sufficient to inhibit microbial growth.

2. Its acidic $p H$ : Honey is characteristically quite acidic, its $\mathrm{pH}$ being between 3.2 and 4.5, which is low enough to be inhibitory to many animal pathogens. The optimum $\mathrm{pH}$ for growth of these species normally falls between 7.2 and 7.4.

3. Hydrogen peroxide: The major antibacterial activity in honey has been found to be due to hydrogen peroxide produced enzymatically in the honey. ${ }^{1}$

\section{Antioxidant}

Propolis is a powerful antioxidant. This effect is due to the high concentration of phenolics and other antioxidant compounds. ${ }^{6}$ Propolis can prevent tissue damage from oxidative stress by decreasing the overproduction of superoxide anion and by restoring respiratory control ration in mitochondrial tissue. According to an Italian study, propolis extract and its active components showed a dosedependent free radical scavenging effect, a significant inhibition of xanthine oxidase activity, and an antilipoperoxidative capacity. $^{2}$

\section{Anti-inflammatory}

The anti-inflammatory activity can be explained by the presence of active flavonoids and cinnamic acid derivatives.

Table 1: Composition of honey

\begin{tabular}{ll}
\hline Composition & Percentage \\
\hline Water & 22.0 \\
Carbohydrates & 79.7 \\
Fiber & 0.0 \\
Protein & 0.2 \\
Ester extract & 0.0 \\
Ash & 0.1 \\
Carbohydrates & Fructose, glucose, sucrose \\
Enzymes & Invertase, amylase, glucose oxidase, catalase, acid phosphorylase \\
Free amino acids & Lysine, histidine, arginine, aspartic acid, threonine, serine, glutamic acid, proline, gycine, alanine, \\
& cystine, valine, methionine, isoleucine, leucine, tyrosine, phenylalanine \\
Minerals & K, Na, Ca, Mg, Fe \\
Vitamins & Riboflavin, niacin, folic acid, pantothenic acid, vitamin $\mathrm{B}_{6}$, vitamin C \\
Antioxidants & Flavonoids, vitamin C, catalase, selenium \\
\hline
\end{tabular}


The former includes acacetin, quercetin, and naringenin the latter includes caffeic acid phenyl ester (CAPE) and caffeic acid (CA). ${ }^{6}$ Ethanolic extract of propolis inhibits hyaluronidase activity. As this enzyme is responsible for several inflammatory processes, propolis holds a great potential as an anti-inflammatory agent. ${ }^{2}$

\section{Antitumor and Antiradiation Effect}

A literature review finds that propolis's pharmacological properties make it safe and effective as an adjunct for patients receiving cancer treatment:

- Biological therapy: Biological therapy works hand in hand with the immune system. Propolis's biological activities, such as antitumoral activity, DNA protection, free-radicals scavenging, and immune stimulation act in synergy with each other and with conventional chemotherapy medication.

- Synergy with chemotherapy: Antioxidants may boost the effects of anticarcinogenic drugs, thus enabling a decrease in the administered dose and in turn leading to a reduction in side effects. They may also influence the response to chemotherapy. ${ }^{9}$

\section{Immunomodulating Effect}

The proliferation of peripheral blood B-lymphocytes and T-lymphocytes in cell culture is stimulated by honey at concentrations as low as $0.1 \%$; and phagocytes are activated by honey at concentrations as low as $0.1 \%$. Honey (at a concentration of $1 \%$ ) also stimulates monocytes in cell culture to release cytokines, tumor necrosis factor (TNF)alpha, interleukin (IL)-1 and IL-6, which activate the immune response to infection. ${ }^{1}$

\section{Antidiabetic and Antihypertensive}

Recent studies have reported that propolis prevented and mitigated diabetes and hypertension, but it remains unclear whether propolis similarly prevents and mitigates the accumulation of visceral adipose tissues and hyperlipidemia. ${ }^{2}$

\section{Healing Activity}

Propolis has been reported to promote epithelial formation as well as vascular and fibroblastic neoformation of the connective tissue. Thus, the topical application of propolis on surgical wounds may promote faster epithelium and connective tissue healing. ${ }^{2}$

\section{DENTAL USES}

\section{Oral Candidiasis}

According to Brazilian researchers, green propolis is effective against oral candidiasis. In this study, all the patients treated with the commercial ethanol propolis extract showed a lesion regression similar to that observed in those patients treated with nystatin. ${ }^{2,9,10}$ Martins et al (2002) assessed the susceptibility of C. albicans strains, collected from HIV-positive patients with oral candidiasis, to a commercial 20\% ethanol propolis extract (EPE) and compared it with various antifungals used in oral candidiasis. EPE inhibited all the C. albicans strained tested. He concluded that commercial EPE could be an alternative medicine in the treatment of candidiasis from HIV-positive patients. $^{11}$

\section{Oral Lichen Planus}

Zyada et al (2012) evaluated the effectiveness of topical mucoadhesive gel-containing propolis in management of patients with atrophic and erosive oral lichen planus and proved that propolis showed to be a promising pharmacological agent for inhibiting epithelial cell proliferation and has anti-inflammatory effect in these oral lichen planus lesions. $^{12}$

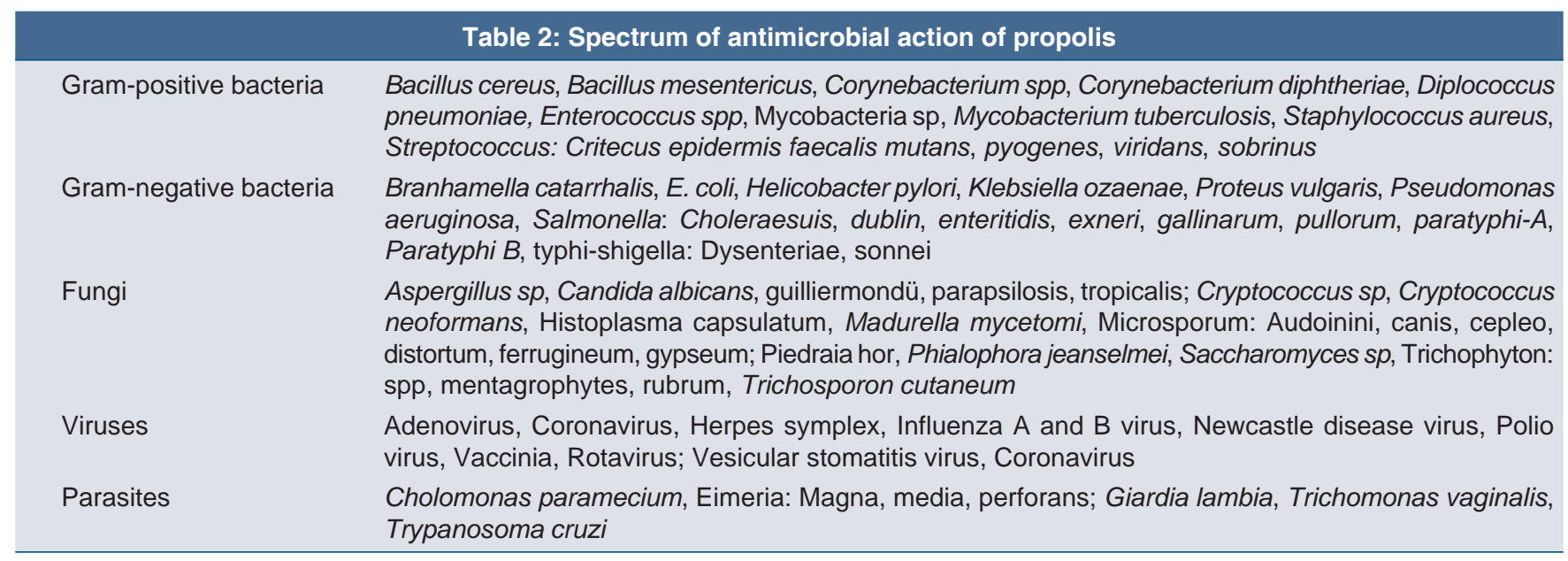




\section{Recurrent Aphthous Stomatitis}

Samet et al (2007) evaluated the potential of a product to reduce the number of outbreaks of recurrent aphthous stomatitis ulcers and showed that propolis is effective in decreasing the number of recurrences and improve the quality of life in patients who suffer from recurrent aphthous stomatitis. ${ }^{11}$

\section{Denture Stomatitis}

Santos et al (2008) evaluated the clinical efficacy of a new Brazilian propolis gel formulation in patients diagnosed with denture stomatitis. All patients treated with Brazilian propolis gel and Daktarin (miconazole gel) had complete clinical remission of palatal edema and erythema. They concluded that Brazilian propolis gel formulation had efficacy comparable to Daktarin and could be an alternative topical choice for the treatment of denture stomatitis. ${ }^{11}$

\section{Radiation Mucositis}

A study was conducted in Malasiya to evaluate the effect of pure natural honey on radiation mucositis. Forty patients were advised to take $20 \mathrm{ml}$ of pure honey 15 minutes before, 15 minutes after and 6 hours postradiation therapy and were evaluated every week for the development of radiation mucositis using the RTOG grading system. The results showed significant reduction in the symptomatic mucositis among honey-treated patients compared to controls. ${ }^{13}$ The anti-inflammatory action and stimulating effect on tissue repair of honey could possibly be of benefit for the relief of oral conditions resulting from radiotherapy and chemotherapy of cancer. ${ }^{1}$

\section{ORAL INFECTIONS, ULCERS AND ORAL SURGICAL WOUND HEALING}

A small clinical trial of the placing honey in the socket before closure of the wound after surgical removal of impacted third molars showed less pain, less incidence of postoperative complications and less swelling in the honey treated group than in the untreated control group. In another study, natural honey showed antibacterial action against anaerobic bacteroides present in dental abscess and osteomyelitis. ${ }^{1}$

A study conducted by Magro-Filho and Carvalho analyzed the effects of propolis mouthrinse on the repair of surgical wounds after sulcoplasty by the modified Kazanjian technique. It was concluded that: (a) The mouth rinse containing propolis in aqueous alcohol solution aided repair of intrabuccal surgical wounds and exerted an analgesic and anti-inflammatory effect, (b) it had a minor irritant effect on infrabuccal surgical wounds, (c) exfoliative cytology showed epithelization of infrabuccal surgical wounds. In histological examination, the effects of topical application of propolis hydroalcoholic solution to dental sockets and skin wounds accelerated epithelial repair after tooth extraction. ${ }^{11}$

A rapid alleviation of pain was observed when the gelled honey was used in a case of erosion of the gum and jaw bone due to infection following surgery with bone grafting to repair damage to the jaw from traumatic injury that had been nonresponsive to any conventional treatment for more than 6 months. The infection cleared and the wound healed up within a month after starting the application of the gelled honey. ${ }^{1}$

Another study was done to determine the effects of the topical administration of propolis and dexamethasone on oral surgical wounds. The study showed that ethanolic extract of propolis demonstrated a greater anti-inflammatory effect and shorter healing time in oral surgical wounds in hamsters, in comparison to dexamethasone in orabase gel. ${ }^{14}$ The features observed when honey is used in treatment of wounds are the rapid clearance of bacteria from colonized and infected wounds, the rapid removal of malodor from wounds, and the debriding effect, which painlessly lifts off slough and necrotic tissue making surgical debridement unnecessary. The rapid rate of healing achieved and its ability to start the healing process in recalcitrant chronic wounds are also noted. It also promotes tissue regeneration through stimulation of angiogenesis and the growth of fibroblasts and epithelial cells, thereby hastening healing and minimizing the need for skin grafting. ${ }^{7}$

\section{ANTICARIOGENIC}

Propolis extracts contains pinocembrin and galangin which inhibit the growth and enzyme activity of Streptococcus mutans. ${ }^{3}$ The production of acid by these bacteria was also inhibited by propolis. ${ }^{1}$

Hayacibara et al (2005) suggested that propolis is a potentially novel anticaries agent by evaluating the influence of propolis on mutans streptococci viability, glucosyl transferases (GTFs) activity and caries development in rats. ${ }^{8,11}$

A study done by Gamal El-Din et al to evaluate and compare the effect of sodium fluoride and bee propolis mouth rinses on salivary S. mutans count showed that the mean of the effect of both mouthrinses on the change in salivary $S$. mutans was statistically significant during the follow-up period. This agreed with the results of Kulkarni and Damle (2003) who revealed that sodium fluoride along 
with its antimicrobial property has remineralization potential. $^{15}$

Simone et al (2006) in his in vitro study indicated that at least two pathways by which propolis extracts exert cariostatic effect, first is the reduction of acid production of $S$. mutans and secondly the inhibition of the proton translocating F-ATPase activities which is one of the mechanisms that $S$. mutans have developed to alleviate their influence of acidification. ${ }^{15}$

\section{PULP CAPPING AGENT}

According to Sabir et al, direct pulp capping with propolis in rats may delay dental pulp inflammation and stimulate reparative dentin. 2,11

\section{INTRACANAL IRRIGANT}

Al-Qathmi and Al-Madi found that propolis was as effective as $\mathrm{NaOCl}$ when used as an antimicrobial irrigant on extracted human teeth. ${ }^{8,11,16}$

\section{INTRACANAL MEDICAMENT}

Oncag et al (2008) compared the antibacterial efficacy of three commonly used intracanal medicaments with propolis against Enterococcus faecalis. ${ }^{8,11}$ and Awawdeh et al (2009) evaluated the effectiveness of propolis and calcium hydroxide as a short-term intracanal medicament against $E$. faecalis. They concluded that propolis is very effective in rapidly eliminating $E$. faecalis and can be used as an alternative intracanal medicament. ${ }^{11}$ As an oily substance, propolis may promote low-speed dissociation and diffusion when used as a component in an endodontic paste for primary teeth. ${ }^{2}$ The association of propolis with calcium hydroxide could aggregate the benefits of each material. ${ }^{2,17}$

\section{DENTINAL HYPERSENSITIVITY}

Mahmoud et al (1999) studied on the effect of propolis on dentinal hypersensitivity in vivo and concluded that propolis had a positive effect in the control of dentinal hypersensitivity. ${ }^{8,11}$ In another in vitro study (Almas et al 2001) using scanning electron microscopy, it was found that propolis occluded the dentinal tubules. ${ }^{11}$ Sales-Peres et al (2010) studied on effect of propolis gel on the in vitro reduction of dentin permeability and concluded that it can be used for partially obliterating the exposed human dentin as its effects are similar to those of potassium oxalate gel. ${ }^{18}$

\section{ANTIPLAQUE}

Murray investigated the effectiveness of a propolis mouthrinse in the inhibition of plaque formation concluded that it was marginally better than negative control. ${ }^{8,11}$ Ozan et al (2007) compared the effects of four different mouthrinse containing propolis solutions and $0.2 \%$ chlorhexidine on oral microorganisms and human gingival fibroblasts. The antibacterial effectiveness of mouthrinse containing propolis samples on oral microorganisms were not found as effective as chlorhexidine, but samples found less cytotoxic on human gingival fibroblasts than chlorhexidine. ${ }^{8,11}$ A study by Koo et al to evaluate the effect of a mouthrinse-containing propolis on 3 days plaque accumulation concluded that propolis containing mouthrinse was efficient in reducing supragingival plaque formation. ${ }^{2,8,11}$

\section{ANTIHALITOSIS}

Candy made with honey is useful for preventing halitosis as it rapidly removes malodor from infected wounds by the antibacterial action. The bacteria would use the glucose in honey in preference to amino acids, and thus would produce lactic acid instead of bad-smelling amines and sulfur compounds. ${ }^{1}$

\section{PERIODONTITIS TREATMENT}

Propolis and honey seems to have in vitro activity against a variety of bacteria that cause periodontal diseases ${ }^{3}$ and the anti-inflammatory activity blocks the direct cause of the erosion of the connective tissues and bone, antioxidants protect the periodontal tissues from the damaging free radicals formed in the inflammatory response and stimulation of the growth of granulation tissue and epithelial cells, aid in repair of the damage done by infecting bacteria and by the free radicals from the inflammatory response to them. ${ }^{1}$ Toker et al (2008) analyzed the morphometric and histopathologic changes associated with experimental periodontitis in rats in response to the systemic administration of propolis and concluded that systemically healthy administered propolis significantly reduced the periodontitis related bone loss. ${ }^{8,11}$

Cairo de Maral et al in a study on periodontitis treatment with Brazilian green propolis gel had found that periodontal diseases are amendable to the treatment by green propolis and had recommend 10\% Brazilian green propolis to be used in conjunction with treatment of chronic periodontitis. ${ }^{2,9,19}$ A study by Amita Coutinho to evaluate the clinical and microbiological parameters of the effect of subgingival irrigation with propolis concluded that prolipsis can be used as an adjuvant to periodontal treatment as it is more effective than scaling and root planning. ${ }^{2,20}$ Another in vitro study was conducted by Gebara et al on propolis extract antimicrobial activity against periodontopathic 
bacteria.The positive results suggest that the propolis extract should be further tested as an adjuvant to periodontal therapy. ${ }^{21}$ Hidaka et al have suggested that propolis may have potential as anticalculus agents in toothpaste and mouthwashes. ${ }^{8}$

\section{A NEW STORAGE MEDIA FOLLOWING AVULSION}

Numerous studies have examined various media in an attempt to determine the ideal material for storage of the avulsed tooth. ${ }^{11}$ Al-Shaher et al examined the tolerance of fibroblasts of the periodontal ligament and dental pulp to propolis and compared with that of calcium hydroxide in vitro. They concluded that propolis can be recommended as a suitable transport medium for avulsed teeth. According to Martin and Pileggi (2004) and Ozan et al (2007) propolis has the ability to serve as a temporary storage medium for the maintenance of periodontal ligament cell viability of avulsed teeth and is more effective storage medium than other groups. 8,11

\section{DISPENSIBLE FORMS FOR TREATMENT IN DENTISTRY}

Propolis mouthwash (5\% aqueous alcohol solution), toothpaste, propolis ointment, propolis intracanal medicament, propolis extract, tablet form, propolis mouth spray.

\section{SAFETY}

In general, propolis is safe. It is a nontoxic substance and does not cause irritation when used as supplements or applied to skin. ${ }^{11}$ Purified bee venom for subcutaneous injection is an FDA-approved product. For Adults and children above 1 year, it is safe when taken orally. But it is possibly unsafe for infants or young children as ingestion of raw honey contaminated with Clostridium botulinum spores can cause botulism poisoning. ${ }^{3}$

In pregnancy and lactation it is possibly safe when apitherapy using bee venom is given as subcutaneous injection by a trained medical professional. But possibly unsafe when apitherapy using bee venom is given by subcutaneous injection in high doses it can increase release of histamine, which can cause uterine contraction. ${ }^{3}$

\section{FUTURE CHALLENGES}

Although many researches have reported the benefits of apitherapy, some disadvantages have also been found. It gets frequently ccontaminated by yeast, fungi and bacterial spores. The physicochemical characteristics of bee products are directly related to the fact that their properties depend on various factors, including the plant sources, climate, environment and bee species. ${ }^{1}$

Patients allergic to bee and bee products are more likely to experience allergic reaction, such as hypersensitivity, asthma, anaphylaxis, and occasionally allergic cheilitis and oral ulcerations. ${ }^{3,4,11}$

\section{CONCLUSION}

- Apitherapy is one of the few natural remedies that maintained its popularity over a long period of time. Scientific research has revealed its antioxidant, antibacterial, antifungal, antiviral, anti-inflammatory, antitumor and immune-modulating properties and in dentistry it is a recent dental research.

- Further research and studies with more significant patient number are necessary for statistical confirmation of its results and further randomized studies are essential to validate the findings.

- However, apitherapy is a gift from mother nature and serve to be a promising alternative medicament for oral diseases.

\section{REFERENCES}

1. Ahuja A, Ahuja V. Apitherapy-A sweet approach to dental diseases: Part I: Honey. J Adv Dent Res 2010 Oct;1(1):81-86.

2. Ahuja V, Ahuja A. Apitherapy-A sweet approach to dental diseases_-Part II: Propolis. J Acad Adv Dent Res 2011 May; 2(2):1-7.

3. Apitherapy-Natural Medicines Comprehensive Database. Available at: www.naturaldatabase.therapeuticresearch.com

4. Scully C. Propolis: A background. Letter Brit Dent J 2006;200: 359-60.

5. Bradbear N. Bees and their role in forest livelihoods. Apitherapy Chapter 12, 2009;119-21. Available at: www.fao.org.

6. Bogdanov S. Propolis: Composition, health, medicine: A Review 2012 Jan 15. Available at: www.bee-hexagon.net

7. Molan PC. Potential of honey in the treatment of wounds and burns. Am J Clin Dermatol 2001;2(1):13-19.

8. Rathod S, Brahmankar R, Kolte A. Propolis: A natural remedy. Indian Journal of Dental Research and Review 2011:50-52.

9. José AS. Brazilian Propolis: A promising adjunct to dental care, cancer treatment, vaccines. AAS Journal 2007;14(1).

10. Santos VR. Oral candidiasis treatment with Brazilian ethanol propolis extract. Phytother Res 2005;19:652-54.

11. Parolia A, Thomas MS, Kundabala M, Mohan M. Propolis and its potential uses in oral health. Int J Med Sci 2010;2(7): 210-15.

12. Zyada MM, El-Said Elewa M, El-Meadawy S, El-Sharkawy H. Effectiveness of topical mucoadhesive gel containing propolis in management of patients with atrophic and erosive oral lichen planus: Clinical and immunohistochemical study. Egypt Dent Assoc 2012;(58)1-3.

13. Biswal BM, Zakaria A, Nik Min A. Topical application of honey in the management of radiation mucositis: A preliminary study. Support Care Cancer 2003;11:242-48. 
14. Lopes-Rocha R, Miranda JL, Lima NL, Ferreira DO, Marinho SA, Verli FD. Effect of topical propolis and dexamethasone on the healing of oral surgical wounds. Wound Healing Southern Africa 2012;5(1):25-30.

15. El-Din NSG, Abbas HM, El-Dokky NA, Soliman NL. Comparative clinical trial on the effect of propolis extract and sodium fluoride mouthrinse on salivary Streptococcus mutans count. Nature and Science 2012;10(4):89.

16. Shingare P, Chaugule V. Comparative evaluation of antimicrobial activity of miswak, propolis, sodium hypochlorite and saline as root canal irrigants by microbial culturing and quantification in chronically exposed primary teeth. GERMS 2011;1(1):12-21.

17. de Rezende GP, da Costa LR, Pimenta FC, Baroni DA. In vitro antimicrobial activity of endodontic pastes with propolis extracts and calcium hydroxide: A preliminary study. Braz Dent J 2008; 19(4):301-05.

18. Sales-Peres SH, Carvalho FN, Marsicano JA, Mattos MC, Pereira JC, Forim MR, et al. Effect of propolis gel on the in vitro reduction of dentin permeability. J Appl Oral Sci 2011;4(19): 318-23.

19. do Amaral C. Periodontitis treatment with Brazilian green propolis gel. Pharmacology 2006;3:336-41.

20. Coutinho A. Honeybee propolis extract in periodontal treatment: A clinical and microbiological study of propolis in periodontal treatment. Indian J Dent Res 2012;23(2):294.
21. Gebara ECE, Lima LA, Mayer MPA. Propolis antimicrobial activity against periodontopathic bacteria. Brazil J Microbiol 2002;33:365-69.

\section{ABOUT THE AUTHORS}

\section{Syeda Arshiya Ara (Corresponding Author)}

Professor, Department of Oral Medicine and Radiology, Al-Badar Rural Dental College and Hospital, Gulbarga, Karnataka, India e-mail: drarshiyazaka@gmail.com

\section{Sajna Ashraf}

Postgraduate Student, Department of Oral Medicine and Radiology Al-Badar Rural Dental College and Hospital, Gulbarga, Karnataka, India

\section{Vini Arora}

Postgraduate Student, Department of Oral Medicine and Radiology Al-Badar Rural Dental College and Hospital, Gulbarga, Karnataka, India

\section{Prakash Rampure}

Postgraduate Student, Department of Oral Medicine and Radiology Al-Badar Rural Dental College and Hospital, Gulbarga, Karnataka, India 